\title{
Pain of US shutdown lingers
}

\section{Researchers fear that continuing budget fights will further harm government-funded science.}

\section{BY LAUREN MORELLO, HEIDI LEDFORD, HELEN SHEN, JEFF TOLLEFSON, ALEXANDRA WITZE \& SARAH ZHANG}

$\mathrm{E}$ cologist Stacy Kim should be preparing to leave for Antarctica, where she was due to begin a study of marine life in the Ross Sea next month. Instead, she is trying to work out how to keep her lab running after her polar plans were cancelled by the US National Science Foundation (NSF), which is struggling to salvage a field season shortened by the 16-day US government shutdown that ended on 17 October.

It is not only the loss of a potential year's worth of data that pains Kim, a researcher at the Moss Landing Marine Laboratories in California, who hoped to use a remotely operated underwater vehicle to monitor everything from Ross Sea phytoplankton to killer whales. The NSF's decision also jeopardizes the flow of grant money to her lab, and she may be forced to lay off technicians. "Most of the people in my lab group have sublet their places for the three months we were supposed to be in Antarctica," she says. "Now I have homeless people," who, she adds, may have to go on unemployment benefits.

But the worst may not be over for US researchers, who face the possibility of another government shutdown in mid-January, when the deeply divided US Congress must agree on a new plan to fund government operations. "I don't think we've learned anything" from the last shutdown, says Matt Hourihan, who directs the research and development

\section{PASSING THE BUCK}

The US Congress has relied heavily on stopgap spending measures to keep the government running.

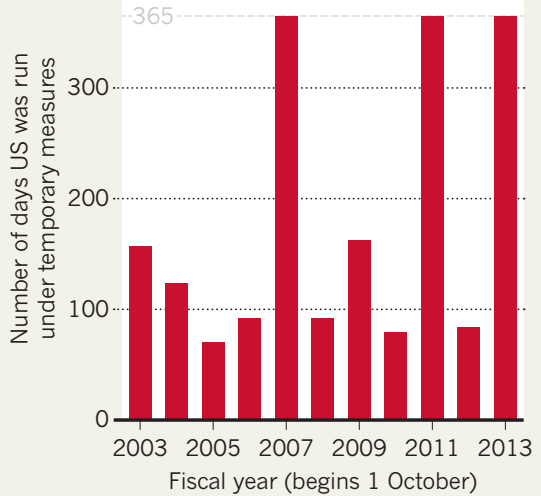

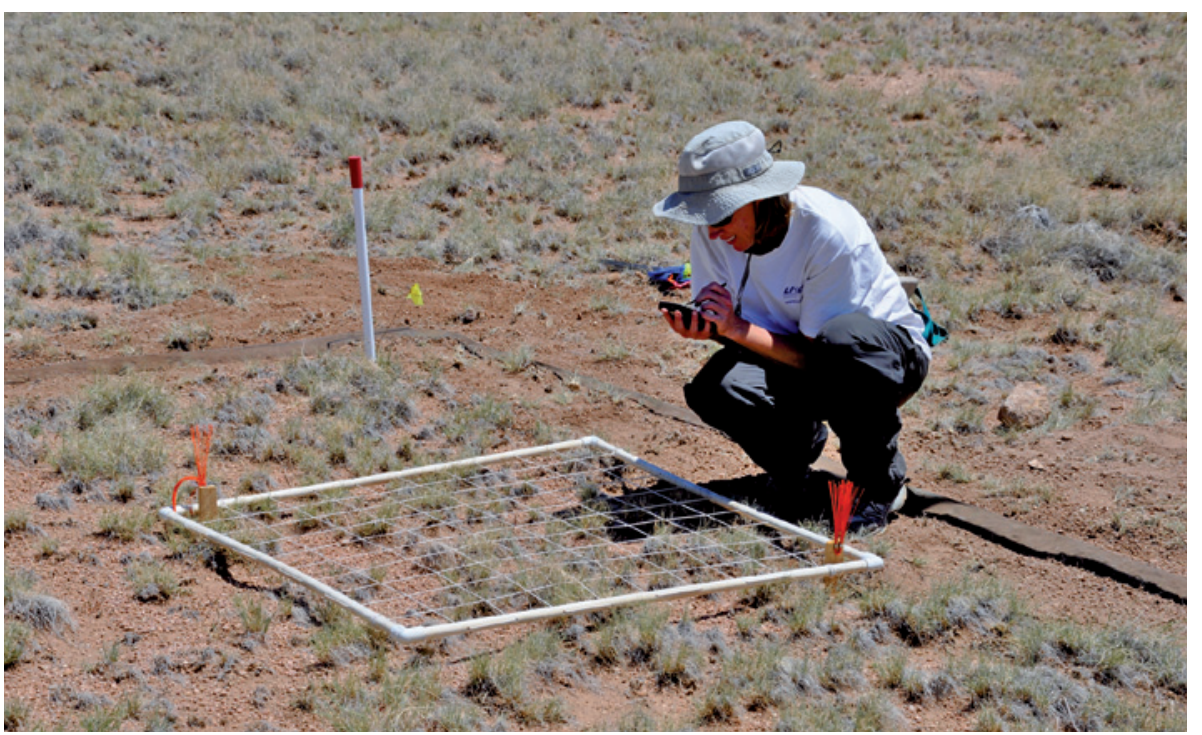

The shutdown disrupted long-term monitoring projects such as a survey of plant life in New Mexico.

budget and policy programme at the American Association for the Advancement of Science (AAAS) in Washington DC. "In many ways, the big fiscal challenges are still there."

These include not only the threat of another shutdown - which would again bring US science agencies' research and grant-making to a halt - but also the scheme known as sequestration. This took a $5.1 \%$ bite out of most US government programmes this year and is poised to claim still more in January. Overall, federal spending on research and development has dropped by an astounding $16.3 \%$ since 2010, according to a recent AAAS analysis, and Congress often chooses to fund the government with temporary spending plans (see 'Passing the buck').

"If I were a young person today, I'd have to wonder if I'd want to go into science in the United States anymore, because the uncertainty has become extraordinary," says Michael Lubell, director of public affairs for the American Physical Society in Washington DC.

At Moss Landing, Kim is struggling to help her students cope with a year's delay to their research plans - an especially difficult task for those pursuing two-year master's degrees, and for an incoming doctoral student. But it is not only young scientists who have lost valuable time and data.

For more than two weeks, Scott Collins, a biologist at the University of New Mexico in Albuquerque, could not access his research site in the Sevilleta National Wildlife Refuge, which closed during the shutdown. That short absence will make it harder to understand how this year's unusually rainy summer affected plant life in arid New Mexico. "We're funded with federal tax dollars to do this research," Collins says. "It matters to us that we do the job well."

And, across the country at a US Department of Agriculture facility in Newark, Delaware, entomologist David Jennings returned to work last week to find that many of his colonies of emerald ash borer larvae had perished. The small crew of 'essential' personnel left to run the lab during the shutdown could not maintain the temperature and feeding schedule that the picky larvae require. Jennings estimates that it will take close to a year to recoup what the lab has lost, delaying research on how to protect US forests from the tree-munching beetle.

Also in jeopardy are some major infrastructure projects currently in development. For example, the shutdown has postponed the final design review for the Large Synoptic Survey Telescope, a ground-breaking project that would allow astronomers to map the southern sky once every three days. The delay could prevent construction from starting next year as planned.

Pieter Tans, who heads the Carbon Cycle Greenhouse Gases group at the National Oceanic and Atmospheric Administration lab in Boulder, Colorado, says that the political manoeuvring that caused the shutdown will also have long-term effects on morale at US research agencies. "It implicitly sent the message to the American people that they don't need all of these government scientists," he Says. - SEE COMMENT P.431 